\title{
The Thermal Decomposition Behavior of Pyrite-Pyrrhotite Mixtures in Nitrogen Atmosphere
}

\author{
Changshun Tian $\mathbb{D}^{1,},{ }^{1,2}$ Yunzhang Rao $\mathbb{D}^{1,2},{ }^{1,2}$ Gang Su, ${ }^{1}$ Tao Huang, ${ }^{1}$ and Cairong Xiang ${ }^{1}$ \\ ${ }^{1}$ Faculty of Resources and Environmental Engineering, Jiangxi University of Science and Technology, Ganzhou 341000, China \\ ${ }^{2}$ Key Laboratory of Mining Engineering of Jiangxi Province, Jiangxi University of Science and Technology, \\ Ganzhou 341000, China \\ Correspondence should be addressed to Changshun Tian; 9320090329@jxust.edu.cn and Yunzhang Rao; 9119870020@ \\ jxust.edu.cn
}

Received 12 October 2021; Revised 18 December 2021; Accepted 23 December 2021; Published 31 January 2022

Academic Editor: Christos Kordulis

Copyright ( $\odot 2022$ Changshun Tian et al. This is an open access article distributed under the Creative Commons Attribution License, which permits unrestricted use, distribution, and reproduction in any medium, provided the original work is properly cited.

\begin{abstract}
To assess the thermal transformation process of common sulfide minerals in a nitrogen atmosphere, thermogravimetric analysis, $\mathrm{X}$-ray diffraction, scanning electron microscopy, and thermogravimetric mass spectrometry are employed to define the influence of the pyrrhotite content in pyrite-pyrrhotite mixtures (mixed minerals). The results indicate that an increase in pyrrhotite content decreases the temperature of the maximum mass loss rate of mixed minerals and reduces its mass loss. The solid-phase transformation of the thermal decomposition of mixed minerals is accelerated because the apparent activation energy of pyrrhotite is lower than that of pyrite and mixed minerals. However, the pyrrhotite makes the mixed minerals easier to sinter and agglomerate, which reduces the total volatilization amount of the gas product, $\mathrm{S}_{2}$; thus, the rate of mass loss decreases.
\end{abstract}

\section{Introduction}

Pyrite and pyrrhotite are common sulfide minerals in mines [1]. Pyrite $\left(\mathrm{FeS}_{2}\right)$ is widely used in rubber and textile, pyrrhotite $\left(\mathrm{Fe}_{1-x} \mathrm{~s}\right)$ is widely used in heavy-metal pollution control, and both of them are widely used in acid production industry [2-5]. Moreover, pyrite and pyrrhotite, as minerals associated with coal, are among the main sources of sulfur dioxide $\left(\mathrm{SO}_{2}\right)$ emissions during coal combustion and environmental pollution [6]. Because $\mathrm{Fe}$ and $\mathrm{S}$ have variable valence properties, pyrite and pyrrhotite exhibit extremely high chemical activities and complex crystal structures. At specific conditions, it will burn or even explode, leading to tragic consequences $[7,8]$. Therefore, it is of great significance to describe the combustion and explosion processes of pyrite and pyrrhotite.

Several articles have been published on the combustion and explosion of a single sulfide mineral. Researchers generally believe that the combustion and explosion processes undergo two stages: thermal decomposition and oxidation; the thermal decomposition process is consistent with the reaction in an inert atmosphere $\left(\mathrm{N}_{2}, \mathrm{He}\right.$, and $\left.\mathrm{Ar}\right)$ [9-11]. Therefore, studying the thermal decomposition process of sulfide minerals is of great value to reveal the mechanism of combustion and explosion.

Considerable research has been carried out on the thermal decomposition behavior of pyrite in an inert atmosphere using a wide range of methods. Many of these results show that the thermal decomposition of pyrite is controlled by a chemical reaction and is a surface first-order reaction $[12,13]$. Generally, it is considered that the thermal decomposition process is as follows: pyrite $\longrightarrow$ pyrrhotite $\longrightarrow$ troilite $(\mathrm{FeS}) \longrightarrow \mathrm{Fe}$, and this process is controlled by the temperature and total S gas pressure in the system [14]. However, Hong et al. [15] believe that the thermal decomposition of pyrite is divided into two steps. The first step is the decomposition of pyrite into pyrrhotite and liquid $\mathrm{S}$ atoms, and the second step is the formation of $\mathrm{S}_{2}(\mathrm{~g})$ by the combination of liquid $S$ atoms and evaporation. When $S$ dissipates quickly, the main reaction stage is dominated by 
Step 1, and the apparent activation energy $(E a)$ is $297 \mathrm{~kJ} /$ mol; when S dissipates slowly, the main reaction stage is conducted by Step 2, and the $E a$ is approximately $112 \mathrm{~kJ} /$ mol. Furthermore, Hoare et al. [16] have studied the reaction mechanism model of a single pyrite particle in an $\mathrm{N}_{2}$ atmosphere and found the rock core shrinkage phenomenon. The decomposition of pyrite into pyrrhotite follows the unreacted core model. The mass loss process of pyrite is divided into two stages. The first stage forms a porous layer of pyrrhotite around each particle, and the second stage is the further decomposition of the material under the pyrrhotite layer. Shi et al. [17] have studied the solid-phase transformation of pyrite in an $\mathrm{N}_{2}$ atmosphere at a temperature gradient of $100^{\circ} \mathrm{C}$ and found that pyrite does not change significantly when the temperature is lower than $500^{\circ} \mathrm{C}$. The pyrite begins to transform into monoclinic pyrrhotite at $500-600^{\circ} \mathrm{C}$, and afterward, hexagonal pyrrhotite is observed at $700-800^{\circ} \mathrm{C}$; at $900^{\circ} \mathrm{C}$, more stable $\mathrm{FeS}$ is formed. Additionally, Wang et al. [18] and Li et al. [19] have applied magnetic technology to identify the thermal decomposition process of pyrite. The study shows that there are two thermal decomposition paths: pyrite $\longrightarrow$ magnetite $\longrightarrow$ pyrrhotite and pyrite $\longrightarrow$ pyrrhotite. Thus, the analysis of the thermal decomposition process of pyrite in an inert atmosphere has not yet been unified.

Pyrrhotite is one of the main species of sulfurous Fe ore in nature; however, few studies have analyzed pyrrhotite as a single object [20]. Selivanov et al. [21] have considered $270^{\circ} \mathrm{C}$ as the limit temperature for $\mathrm{Fe}_{7} \mathrm{~S}_{8}$ to remain stable. Schwarz, $\mathrm{Li}$, Powell, and so on [22-24] have concluded that pyrrhotite undergoes a monoclinic to hexagonal transformation at $300-320^{\circ} \mathrm{C}$. Kennedy et al. [25] believe that pyrrhotite and elemental $\mathrm{S}$ react at approximately $500^{\circ} \mathrm{C}$ to generate pyrite. Furthermore, as the temperature increases, the phase of pyrrhotite changes between S and Fe [26].

Although the thermal decomposition of pyrite and pyrrhotite has been studied in detail, it is well known that the thermochemical reactions of mixed-mineral sulfide ores are more complex than those of single-mineral samples. Yang et al. [27] have found that an increase in the quality fraction of $\mathrm{FeS}$ in an $\mathrm{FeS}-\mathrm{FeS}_{2}$ mixture increases the specific surface area, total pore volume, and adsorption capacity of mixed minerals. Almeida et al. [20] have proved that the combination of pyrite and pyrrhotite is beneficial to the production of $S$ by electrochemical experiments. Further, under opencircuit conditions, when pyrite and pyrrhotite are in contact, galvanic cells are produced between the minerals; this is because the reduction rate of $\mathrm{Fe}$ ions on the surface of pyrite is greater than that on the surface of pyrrhotite; thus, the dissolution rate of FeS in the system increases. Moreover, the addition of pyrrhotite increases the concentration of Fe ions, and thereafter, reversible half-reactions occur, leading to the inhibition of FeS formation.

The purpose of this study is to determine the influence of pyrrhotite content on the thermal decomposition reaction of pyrite-pyrrhotite mixtures (mixed minerals) as the basis for the next step in revealing the combustion and explosion mechanism of the mixed minerals. Therefore, thermogravimetric analysis (TGA), X-ray diffraction (XRD), scanning electron microscopy (SEM), thermogravimetric mass spectrometry (TG-MS), and other characterization methods were applied to determine the causes of the influence by analyzing solid and gas products and calculating the apparent activation energy.

\section{Materials and Methods}

2.1. Materials and Characterization. The samples of pyrite and pyrrhotite were natural minerals, and they were purchased from a stone specimen firm in Guangdong Province, China. To reduce the mechanically activated influence on the thermal decomposition of ore dust samples [28], after coarse crushing in a laboratory, the ore dust samples were manually ground using a corundum mortar. The samples were broken into relatively small particles for the thermal decomposition analysis; they were sieved using a 200 -mesh $(75 \mu \mathrm{m})$ standard sieve. Subsequently, the screened pyrite and pyrrhotite were mixed in mass ratios of $1: 0.1,1: 0.25,1: 0.5,1: 0.75,1: 1,1: 1.25,1$ : $1.5,1: 1.75$, and $1: 2$, respectively. A laser diffraction analyzer (2000E, Jinan Winner, China) was employed to analyze the particle sizes of pyrite, pyrrhotite, and pyritepyrrhotite mixtures with a mass ratio of $1: 1$ (referred to as mixed minerals $(1: 1)$ ). The results are presented in Table 1 and Figure 1. The particle size distribution of most dust particles was below $45 \mu \mathrm{m}$, and the median particle size was below $33 \mu \mathrm{m}$. SEM (MLA650 F, FEI, USA) was used to analyze the surface structure of the ore dust. The results are shown in Figure 2. The pyrite and pyrrhotite samples showed inhomogeneous particle sizes and irregular shapes. The particle size of some mineral samples under the 200mesh standard sieve was larger than $75 \mu \mathrm{m}$ because of the irregular structure. After comparing the results in Figures 1 and 2, it was observed that the result of the particle size analysis of the ore dust samples was in good agreement with the scanning microscopy results. Additionally, the test samples were not dried. Therefore, after drying the samples in a constant-temperature drying oven at $80^{\circ} \mathrm{C}$ for $24 \mathrm{~h}$, the moisture contents of the pyrite and pyrrhotite samples were measured. The results showed that the two minerals were almost free of moisture.

The main mineral components of the three samples were identified by XRD (Empyrean, PANalytical, Holland) at room temperature of $27^{\circ} \mathrm{C}$. The results showed that $\mathrm{FeS}_{2}$ was the main component in the pyrite, accompanied by a small amount of silica $\left(\mathrm{SiO}_{2}\right)$, and $\mathrm{Fe}_{7} \mathrm{~S}_{8}$ was the main component in the pyrrhotite, accompanied by a small amount of $\mathrm{FeS}_{2}$ and $\mathrm{SiO}_{2}$, as shown in Figure 3. The $\mathrm{Fe}$ content in the minerals was determined by titration (implementing standards of GB/T 6730.65-2009 [29]), and the content of S in the minerals was determined by iodometry (implementing standards of YS/T575.17-2007 [30]). The contents of Fe and $S$ in pyrite and pyrrhotite were $45.74 \%$ and $58.23 \%$ and $53.02 \%$ and $38.91 \%$, respectively. The ratios of $\mathrm{S}$ to $\mathrm{Fe}$ in pyrite and pyrrhotite were 2.0285 and 1.1694, respectively, which were in accordance with the stoichiometric values of pyrite $\left(\mathrm{FeS}_{2}\right)$ and pyrrhotite $\left(\mathrm{Fe}_{7} \mathrm{~S}_{8}\right)$; the test results were consistent with those of the XRD analysis. 
TABLE 1: Summary of the laser particle size analysis results of the ore dust samples.

\begin{tabular}{lccccccc}
\hline Sample type & $D_{90} / \mu \mathrm{m}$ & $D_{50} / \mu \mathrm{m}$ & $D_{10} / \mu \mathrm{m}$ & $\begin{array}{c}S / V \\
\left(\text { specific surface area) } /\left(\mathrm{cm}^{2} \mathrm{~cm}^{-3}\right)\right.\end{array}$ & $<10 \mu \mathrm{m} / \%$ & $\begin{array}{c}10-45 \mu \mathrm{m} / \% \\
45-100 \mu \mathrm{m} / \%\end{array}$ & $\begin{array}{c}100-200 \\
\mu \mathrm{m} / \%\end{array}$ \\
\hline Pyrite & 91.94 & 29.04 & 3.551 & 5958.29 & 23.37 & 40.61 & 28.52 \\
Mixed minerals $(1: 1)$ & 79.47 & 24.11 & 2.880 & 6854.01 & 27.48 & 46.38 & 23.02 \\
Pyrrhotite & 80.32 & 28.04 & 3.412 & 6200.91 & 24.86 & 42.76 & 27.32 \\
\hline
\end{tabular}

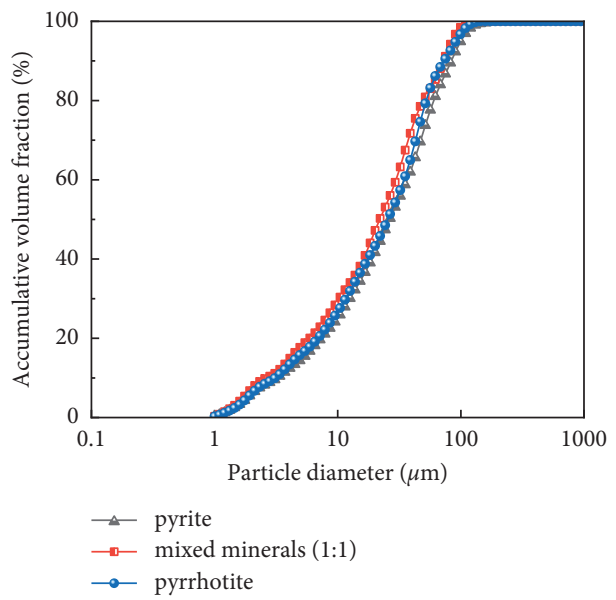

Figure 1: Particle size analysis curves of the ore dust samples.

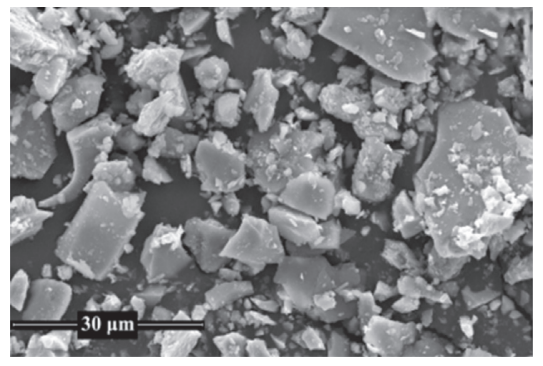

(a)

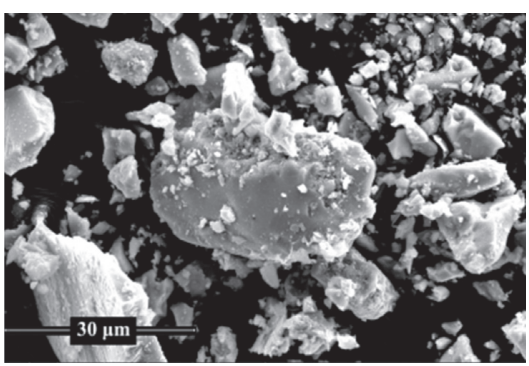

(b)

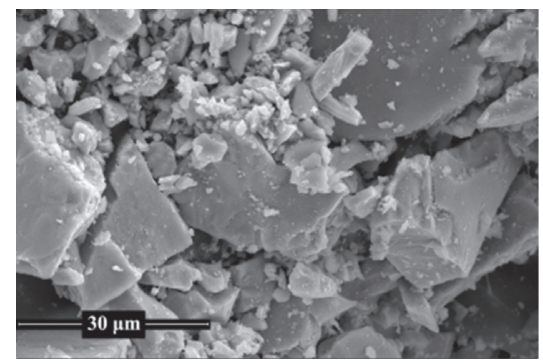

(c)

Figure 2: Surface structure of the ore dust samples: (a) pyrite, (b) mixed minerals (1:1), and (c) pyrrhotite.

2.2. Experimental Methods. All experiments were carried out in a $99.99 \%$ pure $\mathrm{N}_{2}$ atmosphere, and the procedure is shown in Figure 4. First, the thermal decomposition of the pyrite, pyrrhotite, and mixed minerals $(1: 1)$ was assessed using a thermal analysis instrument (TG/DTA6300, PE, USA). To ensure accurate results, the experiments were conducted in strict accordance with the instrument operating procedures. For each test, the mass of the mineral dust was 5-10 mg, the nitrogen flow was $200 \mathrm{~mL} / \mathrm{min}$, and the temperature range was $30-1100^{\circ} \mathrm{C}$. The experiments were conducted at a heating rate of $10{ }^{\circ} \mathrm{C} / \mathrm{min}$. Under the same scheme, experiments were carried out on mixed minerals with other mass ratios, and the influence of the pyrrhotite content in the mixed minerals was determined.

To analyze the influence mechanism, a tube furnace (TL1700, Nanjing Huike Electric Furnace Inc., China) was used with a gas flow of $200 \mathrm{~mL} / \mathrm{min}$, a heating rate of $10{ }^{\circ} \mathrm{C} /$ $\mathrm{min}$, and the temperature selected in the thermal analysis test results. The phase variable of the mixed minerals $(1: 1)$ was investigated by comparing pyrite with pyrrhotite. In the test, $2.5 \mathrm{~g}$ of the three kinds of mineral samples was placed in an $80 \times 40 \times 17 \mathrm{~mm}$ trapezoidal corundum crucible. After reaching the test temperature, the temperature was maintained for $20 \mathrm{~min}$, and the product was continuously ventilated until it was cooled to room temperature. The solid products were characterized by XRD and SEM (MLA650 F, FEI, USA). For the TG-MS (STA449F3-QMS403, NETZSCH, Germany), $10 \mathrm{mg}$ of each of the three ore dust samples was used. The gas flow rate of the TG was $50 \mathrm{~mL} / \mathrm{min}$, the gas flow rate of the MS was $20 \mathrm{~mL} / \mathrm{min}$, and the heating rates were 10 ${ }^{\circ} \mathrm{C} / \mathrm{min}$, according to the conclusion of literature [17-24]. The changes in $S$ and $S_{2}$ in the gas-phase products of the thermally decomposed mixed minerals $(1: 1)$ were investigated in real time, and pyrite and pyrrhotite were compared.

The magnetic measurements were carried out using a physical property measurement system (PPMS, Quantum Design Inc., China) within a magnetic field of $1 \mathrm{~T}$ at a stable temperature of $27^{\circ} \mathrm{C}$. 


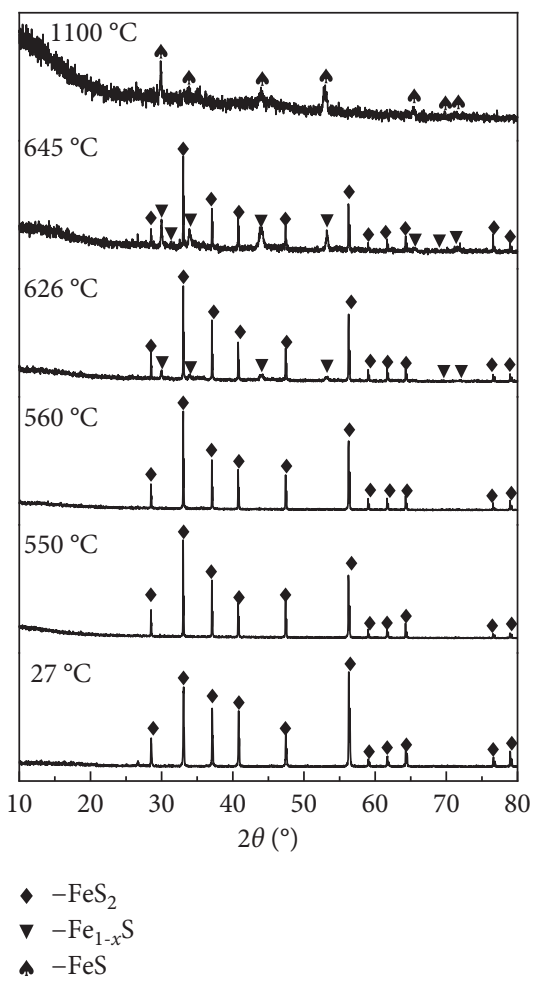

(a)

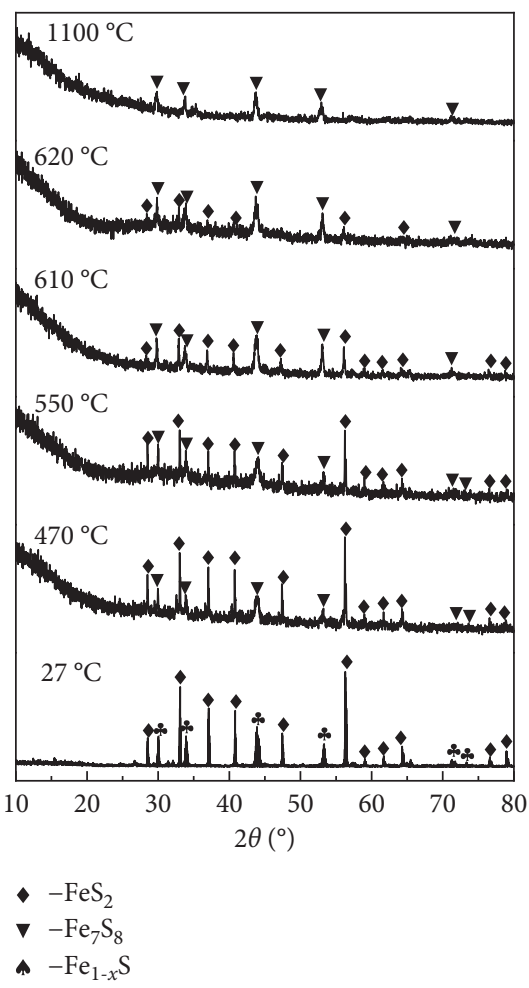

(b)

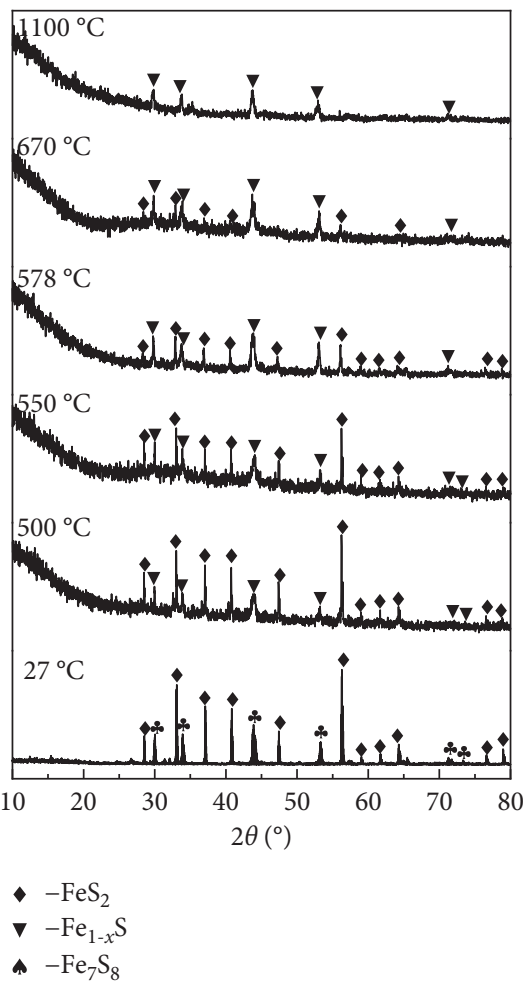

(c)

FIGURE 3: The XRD analysis results of the solid-phase products at the end temperatures of the different stages and the peak temperature of the DTG of the thermal decomposition of the ore dust samples: (a) pyrite, (b) mixed minerals $(1: 1)$, and (c) pyrrhotite.

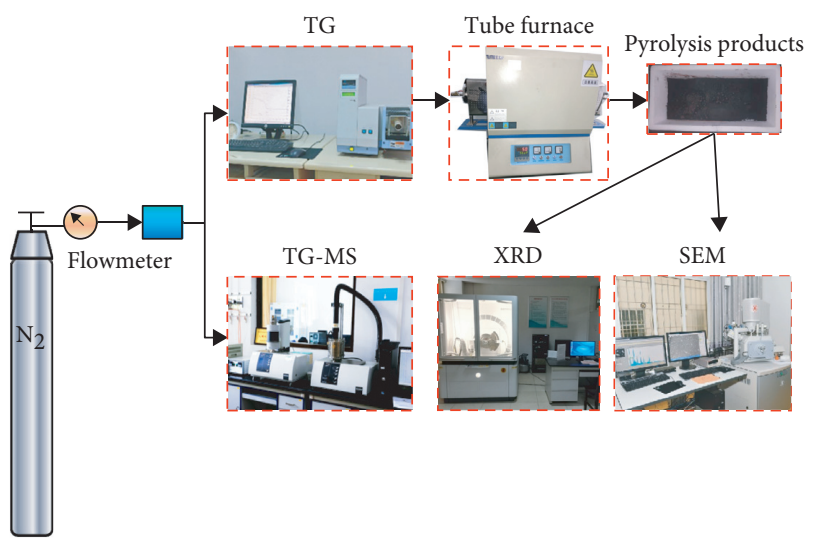

FIGURE 4: Experimental instrument and process.

\section{Results and Discussion}

3.1. Thermal Decomposition Behavior of Each Mineral in $\mathrm{N}_{2}$ Atmosphere: Pyrite, Mixed Minerals (1:1), and Pyrrhotite. The thermal analysis results for pyrite, mixed minerals $(1: 1)$, and pyrrhotite are shown in Figure 5. The thermal decomposition process of the three ore dust samples was accompanied by mass loss and could be divided into three stages. The total mass loss of pyrite $(\Delta m=25.22 \%)$ was higher than that of the mixed minerals $(1: 1)(\Delta m=16.12 \%)$ and pyrrhotite $(\Delta m=5.81 \%)$.

Only a small amount of mass loss occurred in the first stage: $2.61 \%, 1.56 \%$, and $0.92 \%$, respectively. The end

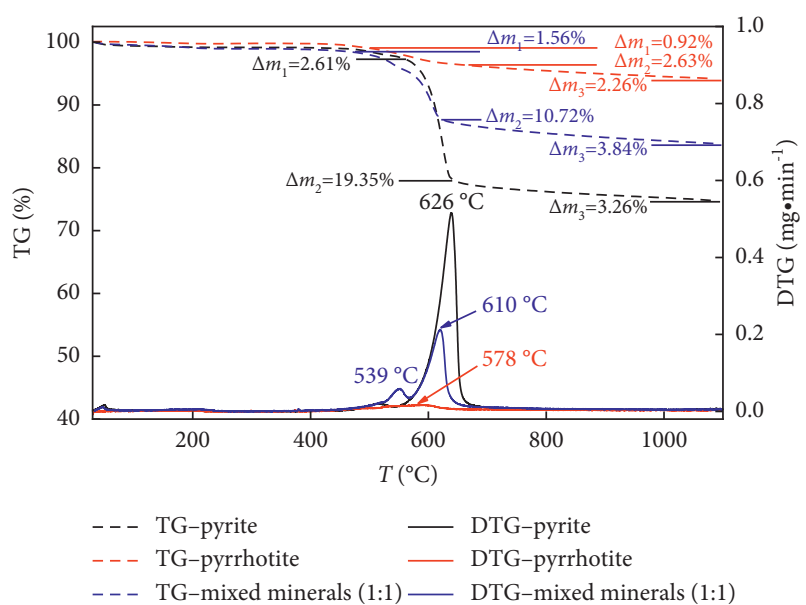

Figure 5: Thermal decomposition of the ore dust samples; $\Delta \mathrm{m}_{1}$, $\Delta \mathrm{m}_{2}$, and $\Delta \mathrm{m}_{3}$ are the first, second, and third stages of mass loss, respectively.

temperatures were 560,470 , and $500^{\circ} \mathrm{C}$, respectively. Because the sample was dried without free water and bound water and the result of S/Fe characterized in Section 2.2 was larger than the theoretical value, there was excess $S$. Therefore, we believe that a small amount of elemental S was volatilized by heating.

The highest mass losses occurred in the second stage, and they were $19.35 \%, 10.72 \%$, and $2.63 \%$, respectively, and the end temperatures were 560,470 , and $500^{\circ} \mathrm{C}$, respectively. 
This trend was attributed to the decomposition of the main minerals in the pyrite dust [31]. The maximum mass loss rates occurred at 602,607 , and $610^{\circ} \mathrm{C}$, which were 0.511 , 0.209 , and $0.0157 \mathrm{mg} / \mathrm{min}$, respectively. Further, the derivative thermogravimetry (DTG) curves showed a peak. Furthermore, it was observed that although the reaction rate of the mixed minerals $(1: 1)$ did not increase and the heating rate remained the same $\left(10{ }^{\circ} \mathrm{C} / \mathrm{min}\right)$, the mixed minerals $(1$ : 1) attained the maximum mass change rate earlier because of the pyrrhotite.

In the third stage, the mass decreased to $3.26 \%, 3.84 \%$, and $2.26 \%$, respectively. Study shows that the mass loss of pyrite is related to the slow and continuous desulfurization of the intermediate pyrrhotite product, and the final product is troilite, which possesses a stable structure and composition [17]. As demonstrated above, the slow and continuous desulfurization reaction of pyrrhotite and mixed minerals $(1: 1)$ occurred simultaneously, and this requires further verification.

3.2. The Influence of Pyrrhotite Content on the Thermal Decomposition of the Pyrite-Pyrrhotite Mixtures. As shown in Figure 6, an increase in the content of pyrrhotite decreases the peak temperature of the thermal decomposition (peak of DTG) of the mixed minerals; this indicates that pyrrhotite accelerates the thermal decomposition of the mixed minerals. Moreover, an increase in the content of pyrrhotite decreased the mass loss of the mixed minerals, which showed that the reaction intensity of pyrrhotite was not as strong as that of pyrite. Further, the reaction of pyrite was more violent, the heat loss was greater, and this has been confirmed in an explosion test in previous literature [32]. Previously, it was considered that the volatilization of volatile gas is the cause of mass loss in the gas-solid reaction of dust thermal decomposition [33]. Therefore, the problem of reaction intensity can be determined from the chemical reaction products, and this phenomenon is discussed in Section 4.1.

\section{The Influence of Pyrrhotite on the Thermal Decomposition Mechanism of the Pyrite- Pyrrhotite Mixtures}

A comprehensive discussion of the thermal decomposition of pyrite and pyrrhotite in the $\mathrm{N}_{2}$ atmosphere was based on the literature data, the solid phase, gas phase, and changes in the surface structure, providing data support for analyzing the effect of pyrrhotite on the thermal decomposition of mixed minerals.

4.1. Pyrite. The changes in the solid phase, gas phase, and surface structure during the thermal decomposition of pyrite at different temperatures are shown in Figures 3(a), 7(a), and $8(\mathrm{a})$, respectively. From $27^{\circ} \mathrm{C}$ to $390^{\circ} \mathrm{C}$, the elemental $\mathrm{S}$ gas curve gradually decreased. The solid-phase analysis results at this temperature showed that pyrite did not decompose, and the melting point of $\mathrm{S}$ was approximately $112.8^{\circ} \mathrm{C}$. This indicated that the mass loss resulted from the volatilization of

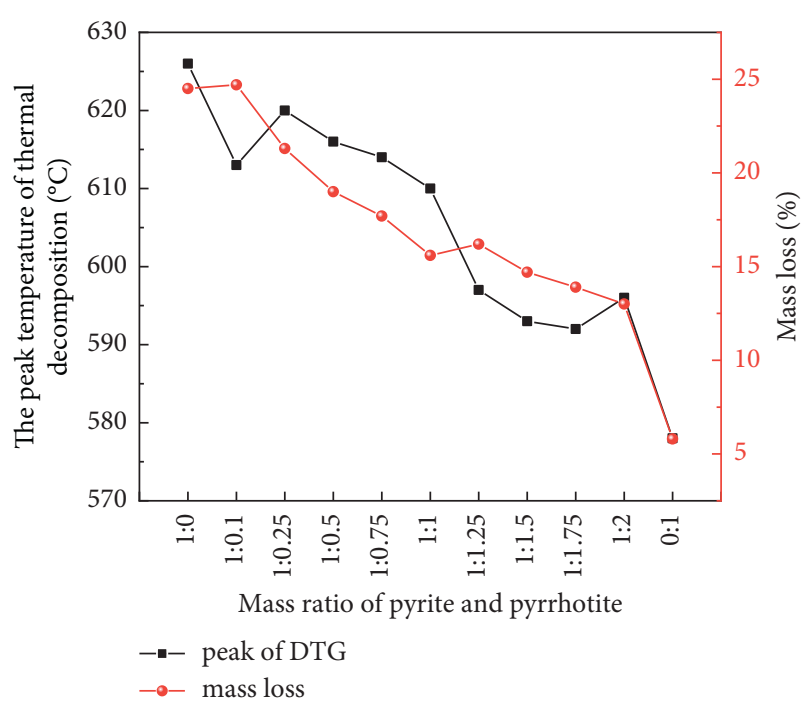

FIgURE 6: The influence of pyrrhotite content on the thermal decomposition of the mixed minerals.

elemental S gas and confirmed the conjecture of mass loss in the first stage, as presented in Section 3.1. The pyrite particles had a smooth surface at $550^{\circ} \mathrm{C}$, which was demarcated with no phase change. At $560^{\circ} \mathrm{C}$, a small number of pores appeared on the surface of the pyrite, and the surface of the finer particles became smooth, accompanied by sintering. Additionally, a small amount of $S_{2}$ gas was emitted from the surface of the pyrite, which showed that the pyrite began to undergo thermal decomposition. Compared with that in literature [17], the temperature range for the conversion of pyrite to pyrrhotite can be compressed to $560-600^{\circ} \mathrm{C}$.

Furthermore, at $626^{\circ} \mathrm{C}$, the pyrite surface pores gradually increased, showing a honeycomb shape. The small particles were agglomerated into blocks, and only the presence of hexagonal pyrrhotite $\left(\mathrm{Fe}_{1-\mathrm{x}} \mathrm{S}\right)$ was detected; there was an endothermic peak in the differential scanning calorimetry (DSC) curve, indicating that the thermal decomposition reaction was the most violent. According to the literature [17], the pyrrhotite produced at $560-626^{\circ} \mathrm{C}$ completed the transformation from monoclinic to hexagonal, the $S_{2}$ peak was narrow with high intensity, and this indicated that $S_{2}$ was the main product of the thermal decomposition of pyrite. At $645^{\circ} \mathrm{C}$, the pores on the surface of the pyrite were completely opened, the pores were shallow, and the bottom of the pores was visible, indicating that the reaction only occurred on the surface. Additionally, the characteristic peaks of pyrite at $645^{\circ} \mathrm{C}$ were significantly lower than those at $626^{\circ} \mathrm{C}$, and the increased characteristic peaks of $\mathrm{Fe}_{1-\mathrm{x}} \mathrm{S}$ indicated that pyrite transformed into hexagonal pyrrhotite.

At $1100^{\circ} \mathrm{C}$, the surface of the pyrite particles was porous, and the particles were approximately spherical; when the particles were further enlarged, a hexagonal columnar shape was observed. The XRD analysis only showed hexagonal troilite $(\mathrm{FeS})$ products, and the thermal decomposition reaction continued. The amount of $S_{2}$ produced exhibited an upward trend, and the height of the $S_{2}$ production trend was equal to the peak value, while the amount of produced $S$ 


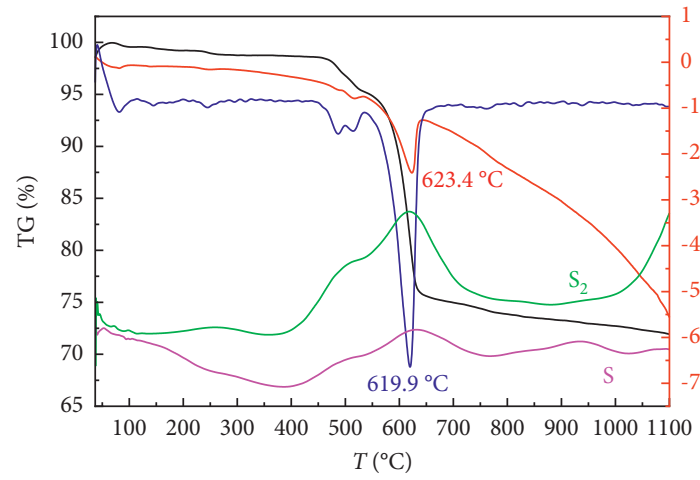

(a)

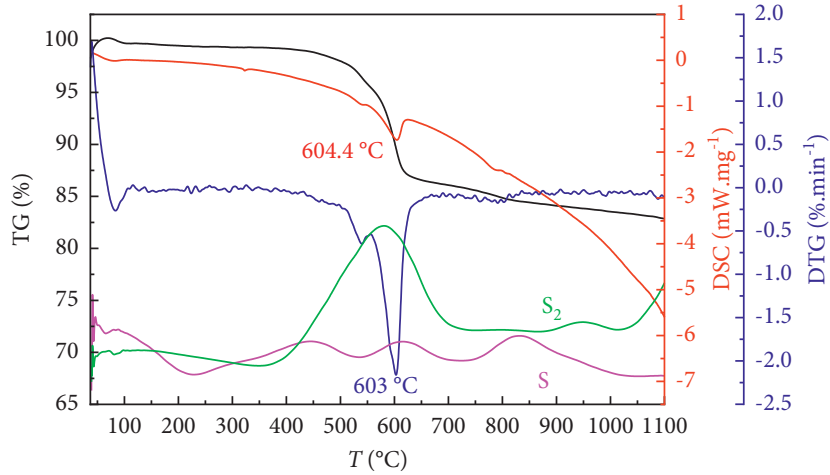

(b)

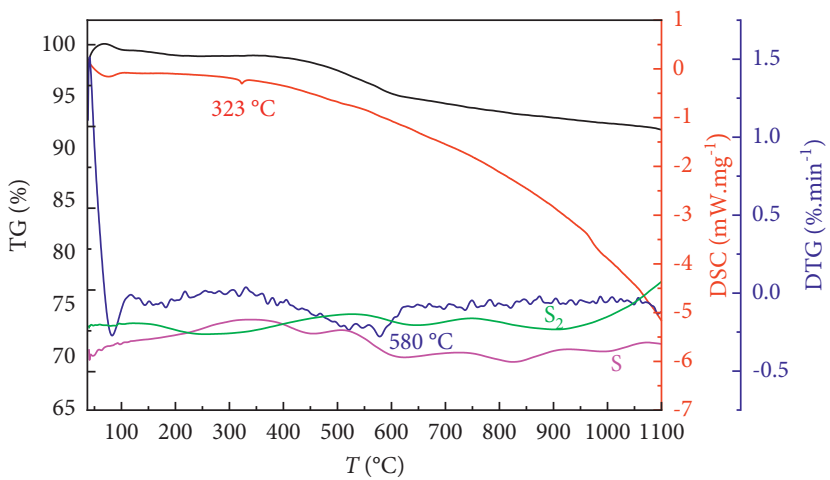

(c)

FIGURE 7: The real-time gas-phase transformation process of thermal decomposition: (a) pyrite, (b) mixed minerals (1:1), and (c) pyrrhotite.

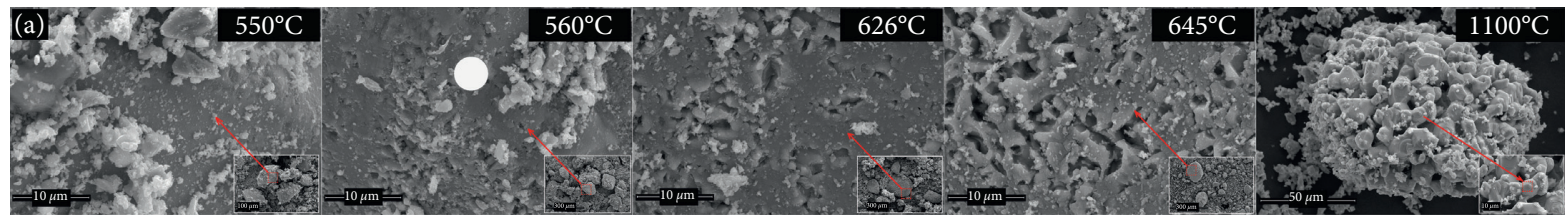

(a)

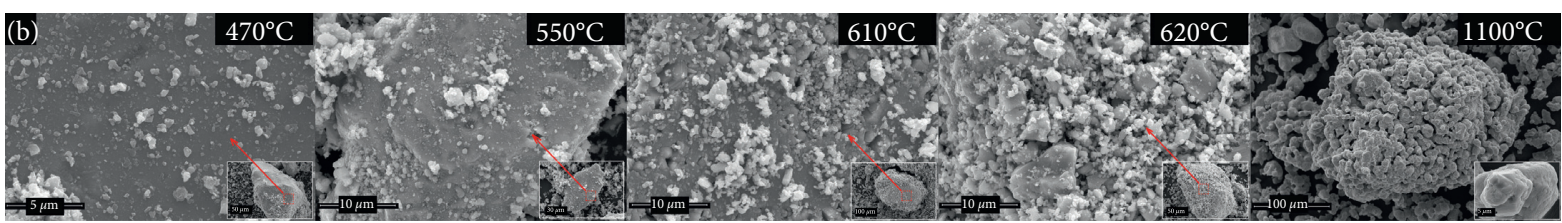

(b)

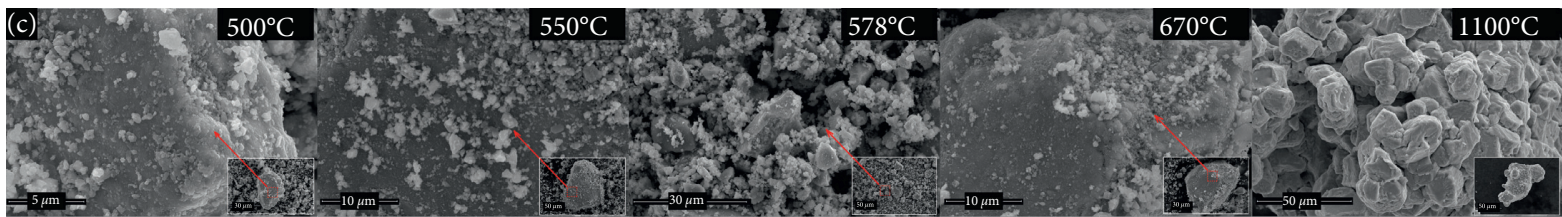

(c)

FIGURE 8: Changes in the surface structure of the thermal decomposition products: (a) pyrite, (b) mixed minerals (1:1), and (c) pyrrhotite.

changed slightly, indicating that the gas product was still dominated by $\mathrm{S}_{2}$. These results are consistent with those reported in literature [17].
In summary, the thermal decomposition of pyrite in the $\mathrm{N}_{2}$ atmosphere was a two-step chemical reaction, which can be described by the following equations: 


$$
\begin{aligned}
(1-x) \mathrm{FeS}_{2}(\mathrm{~s}) & =\mathrm{Fe}_{1-x} \mathrm{~S}(\mathrm{~s})+(0.5-x) \mathrm{S}_{2}(\mathrm{~g}), \\
\mathrm{Fe}_{1-x} \mathrm{~S}(\mathrm{~s}) & =(1-x) \mathrm{FeS}(\mathrm{s})+0.5 x \mathrm{~S}_{2}(\mathrm{~g}) .
\end{aligned}
$$

4.2. Pyrrhotite. Figures $3(\mathrm{c}), 7(\mathrm{c})$, and $8(\mathrm{c})$ show the variations in the solid phase, gas phase, and surface structure during the thermal decomposition of pyrrhotite at different temperatures, respectively. At $323^{\circ} \mathrm{C}$, an endothermic peak appeared in the DSC curve of pyrrhotite, the pyrrhotite was transformed from monoclinic to hexagonal, and $S_{2}$ was still the main gas product. These findings were consistent with those reported in literature [21-24]. At $500^{\circ} \mathrm{C}$, the surface of the particles was smooth and did not agglomerate, which was different from that of pyrite. Fine particle agglomeration was more obvious at $550^{\circ} \mathrm{C}$, and the surface of large particles was still smooth; this was due to the relatively strong magnetism of pyrrhotite [18]. Additionally, the peak value of $\mathrm{FeS}_{2}$ increased at $500^{\circ} \mathrm{C}$ and $550^{\circ} \mathrm{C}$, indicating that monoclinic pyrrhotite, $\mathrm{Fe}_{7} \mathrm{~S}_{8}$, decomposed to form a small amount of $\mathrm{FeS}_{2}$. This phenomenon is consistent with previously reported experimental results [24]. The aggregated small particles became loose and porous at $578^{\circ} \mathrm{C}$, indicating that most of the gas was generated and volatilized out of the particles through the pore channels. The XRD results showed that $\mathrm{Fe}_{1-x} \mathrm{~S}$ was produced by the thermal decomposition of $\mathrm{FeS}_{2}$ and $\mathrm{FeS}_{2}$ in the original ore sample. This phenomenon was in good agreement with the above-mentioned thermal decomposition of pyrite.

Nevertheless, at $670^{\circ} \mathrm{C}$, most of the fine pyrrhotite particles agglomerated into spheres because of pyrolysis. The surface of the fine particles was rough and porous, the surface of the large particles remained unchanged, and only $\mathrm{Fe}_{1-\mathrm{x}} \mathrm{S}$ was produced. At $1100^{\circ} \mathrm{C}$, particle agglomeration was more obvious. The particle surface was the same as that of pyrite, presenting a hexagonal columnar shape. Only hexagonal $\mathrm{Fe}_{1-\mathrm{x}} \mathrm{S}$ was found in the residue by XRD analysis. Further, at $578-1100^{\circ} \mathrm{C}$, the phase of pyrrhotite changed between $\mathrm{S}$ and $\mathrm{Fe}$ as the temperature increased [26]; at $1100^{\circ} \mathrm{C}$, only troilite existed in the thermal decomposition products of pyrite, as presented in Section 4.1. However, it is not shown in the XRD analysis results of the pyrrhotite thermal decomposition. The above phenomenon occurred because the $\mathrm{Fe}_{1-\mathrm{x}} \mathrm{S}$ peak masked a small amount of FeS peak formed by the thermal decomposition of pyrite. References [34, 35] believe that XRD analysis has errors in distinguishing the phases of adjacent objects through diffraction peaks. Therefore, the XRD analysis results in this study were acceptable. Compared with the peaks of $S$ and $S_{2}$ at $500-1100^{\circ} \mathrm{C}$, the peak of $S_{2}$ was steeper; therefore, $S_{2}$ remained the main gas product.

In summary, the thermal decomposition reaction equations of pyrrhotite in the $\mathrm{N}_{2}$ atmosphere are shown as follows:

$$
\begin{aligned}
(1-x) \mathrm{Fe}_{7} \mathrm{~S}_{8}(\mathrm{~s})= & 7 \mathrm{Fe}_{1-x} \mathrm{~S}(\mathrm{~s}) \\
& +(0.5-4 x) \mathrm{S}_{2}(\mathrm{~g}), \\
\mathrm{Fe}_{1-x} \mathrm{~S}(\mathrm{~s})+(1-2 x) \mathrm{S}(\mathrm{s})= & (1-x) \mathrm{FeS}_{2}(\mathrm{~s}) .
\end{aligned}
$$

4.3. Pyrite-Pyrrhotite Mixtures. In the thermal decomposition process, the solid phase, gas phase, and surface structure changes of the mixed minerals $(1: 1)$ at different temperatures are shown in Figures 3(b), 7(b), and 8(b). At $470^{\circ} \mathrm{C}$, the surface of the large particles was smooth without pores, and the particles were distinct with no obvious change. At $550^{\circ} \mathrm{C}$, micropores appeared on the surface of the large particles, and finer particles were adsorbed on the surface of the large particles. The results of the XRD analysis at $470^{\circ} \mathrm{C}$ and $550^{\circ} \mathrm{C}$ showed that hexagonal $\mathrm{Fe}_{1-\mathrm{x}} \mathrm{S}$ and $\mathrm{FeS}_{2}$ were present. Further, the peak value of pyrite decreased, indicating the transformation of pyrite and the formation of pyrrhotite. However, at $560^{\circ} \mathrm{C}$, part of the peak value of single pyrite decreased, and part of the peak value increased; the $\mathrm{Fe}_{1-\mathrm{x}} \mathrm{S}$ phase was not formed, indicating that the addition of pyrrhotite was conducive to the thermal decomposition of pyrite, which can explain the experimental phenomenon presented in Section 3.2. Additionally, the peak of pyrrhotite began to decrease, indicating that the transformation from monoclinic to hexagonal was completed. It was confirmed in a previous report [20] that the combination of pyrite and pyrrhotite is beneficial to the generation of $S$, and the curve of the gas product, $S_{2}$, showed an upward trend, further confirming the occurrence of the reaction.

Moreover, at $610^{\circ} \mathrm{C}$, the pores on the surface of the large particles increased, and the agglomeration of small particles was observed. There was an endothermic peak in the DSC curve, and a large amount of $S_{2}$ gas was generated near this temperature. At $620^{\circ} \mathrm{C}$, the pores on the surface of the large particles increased and were completely opened. Small particles were adsorbed on the surface of the large particles. However, the pores indicated that the reaction occurred not only on the surface of small particles but also on the surface of large particles at the relatively low part of the adsorption layer. The peak value of $\mathrm{FeS}_{2}$ in the mixed minerals $(1: 1)$ was lower than that in the single pyrite, which indicated that pyrrhotite was beneficial to the thermal decomposition of pyrite at high temperatures. At $1100^{\circ} \mathrm{C}$, the surfaces of the particles were porous and honeycomb-like. Occasionally, some particles were not honeycomb-like. The pores of the mixed minerals were less than those of pyrite, which showed that the reaction intensity of the mixed ore was lower than that of pyrite. When a single particle was further enlarged, it was found that its shape was hexagonal columnar, and the $\mathrm{XRD}$ results were the same as those of pyrrhotite: only hexagonal $\mathrm{Fe}_{1-\mathrm{x}} \mathrm{S}$ was observed. This may be because the addition of pyrrhotite inhibited the formation of FeS from pyrite [20]; however, a small amount of FeS peaks was masked by $\mathrm{Fe}_{1-\mathrm{x}} \mathrm{S}$. Additionally, the $\mathrm{S}_{2}$ analysis curve still showed an upward trend, indicating that the mixed minerals underwent decomposition reaction, which was the same for pyrite and pyrrhotite at temperatures higher than $1100^{\circ} \mathrm{C}$.

In summary, the thermal decomposition reaction equation of the pyrite-pyrrhotite mixtures in the $\mathrm{N}_{2}$ atmosphere is shown in the following equation:

$$
\begin{aligned}
(1-x) \mathrm{FeS}_{2}(\mathrm{~s})+(1-x) \mathrm{Fe}_{7} \mathrm{~S}_{8}(\mathrm{~s}) & =8 \mathrm{Fe}_{1-x} \mathrm{~S}(\mathrm{~s}) \\
& +(1-5 x) \mathrm{S}_{2}(\mathrm{~g}) .
\end{aligned}
$$


4.4. Verification of the Analysis Results. To verify the accuracy of the thermal decomposition products of pyrite, mixed minerals $(1: 1)$, and pyrrhotite at $1100^{\circ} \mathrm{C}$, the magnetic analysis of the three products was carried out, and the results are shown in Figure 9. The magnetic properties of the three products were considerably weak and almost negligible. However, as shown in Figure 9, the thermal decomposition products of the pyrrhotite and mixed minerals $(1: 1)$ show enhanced antidemagnetization abilities and are equal. In the XRD analysis results, hexagonal pyrrhotite $\mathrm{Fe}_{1-\mathrm{x}} \mathrm{S}$ was observed. The thermal decomposition products of pyrite exhibited a weak antidemagnetization ability. In the XRD analysis results, FeS was observed. The results of the validity test are consistent with the results of literature [22]; therefore, the thermal analysis XRD results are acceptable.

Additionally, the above-mentioned TG and TG-MS tests were successively carried out, and the errors of the DTG peak value were $0.97 \%, 1.15 \%$, and $0.34 \%$, respectively. The errors may be caused by the different ventilation rates of $\mathrm{N}_{2}$ and the different masses of the analysis samples [36], which was considered acceptable because the heating rate was $10^{\circ} \mathrm{C} / \mathrm{min}$.

\section{Kinetic Mechanism and Model}

5.1. Kinetic Mechanism Analysis. The apparent activation energy $(E a)$, as a research object, can significantly describe the thermodynamic mechanism of nonisothermal and heterogeneous reaction systems [37]. Hoare et al. [16] and Lv et al. [38] believed that the thermal decomposition process of pyrite could be described by the shrinking sphere model and three-dimensional diffusion model; the decomposition process of pyrrhotite corresponds with the three-dimensional diffusion model. Combined with the analysis of the chemical mechanism presented in Section 4, the Coats-Redfern method was used to calculate the $E a$ of pyrite, mixed minerals $(1: 1)$, and pyrrhotite at $560-630^{\circ} \mathrm{C}$, as shown in the following equation:

$$
\ln \left[\frac{g(a)}{T^{2}}\right]=\ln \left(\frac{A R}{\beta E a}\right)-\frac{E a}{R T},
$$

where $\beta$ is the heating rate $\left({ }^{\circ} \mathrm{C} / \mathrm{min}\right), A$ is the preexponential factor $\left(\mathrm{min}^{-1}\right), E a$ is the apparent activation energy of the reaction $(\mathrm{kJ} / \mathrm{mol}), R$ is the universal gas constant $(8.314 \mathrm{~J} /$ $\left.\mathrm{K} \cdot \mathrm{mol}^{-1}\right), T$ is the absolute temperature $(K), g(\alpha)$ is the integral function of the reaction model, and $a$ is the decomposition conversion rate of the three samples (\%), $a=\left(m_{0}-m_{t}\right) /\left(m_{0}-m_{\infty}\right), m_{0}$ is the initial mass of the sample, $m_{t}$ is the mass of the sample at time $t$, and $m_{t}$ is the final mass of the sample.

The solution process was to draw the $g(a) / T^{2}-(1 / T)$ curve according to the integral function and 39 common $g(a)$ listed in reference [37]. Ea was obtained according to the slope of the straight line, and $A$ was obtained according to the intercept. After calculating $E a$ of the three ore samples, the results are presented in Table 2. The table lists models a, $b$, and $e$ described in literature $[16,38]$ and lists models $a, c$, and $d$ of 39 common functions with the highest

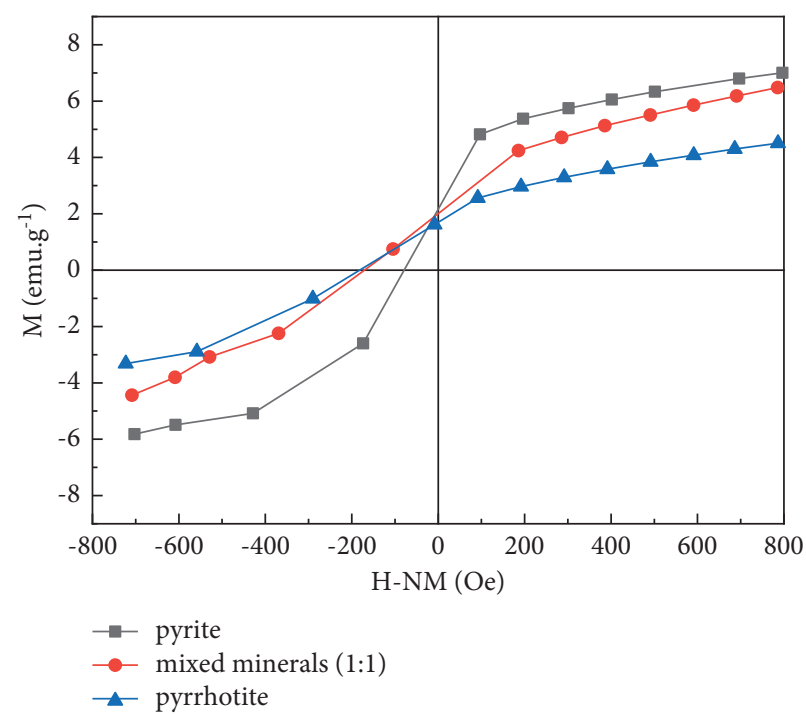

Figure 9: Magnetic analysis results of the thermal decomposition products at $1100^{\circ} \mathrm{C}$. The magnetic measurements were carried out at a stable temperature of $27^{\circ} \mathrm{C}$.

correlation coefficient, whichever is higher. After the comparison, the $E a$ values of pyrite, mixed minerals $(1: 1)$, and pyrrhotite were calculated to be $147.18,87.20$, and $27.21 \mathrm{~kJ} / \mathrm{mol}$, respectively. The results showed that pyrrhotite contained more active reactants and required less energy for thermal decomposition reactions, and chemical reactions were more likely to occur; these findings are consistent with the experimental results.

5.2. Kinetic Process Model and Influence Mechanism. Studies have shown that the surface reaction of pyrite and pyrrhotite dust in an $\mathrm{N}_{2}$ atmosphere is the main reaction $[12,13]$. Although the pyrite and pyrrhotite used in this study contained a small amount of $\mathrm{SiO}_{2}$, it has been proven that $\mathrm{SiO}_{2}$ is an inert material [39] and does not participate in the reaction. From the XRD and TG-MS analysis results, it was observed that the thermal decomposition reaction of pyrite, pyrrhotite, and mixed minerals was a gas-solid twophase reaction, and the pyrite and pyrrhotite decomposition processes were included in the thermal decomposition reaction of mixed minerals. Using the SEM analysis results, the thermal decomposition kinetic process of mixed minerals in the $\mathrm{N}_{2}$ atmosphere was analyzed and presented in this section, as shown in Figure 10.

The thermal decomposition process of the mixed minerals consisted of three stages. In the first stage, when pyrite was heated, elemental S volatilized from the cracks of pyrrhotite fine particles and the surface where large pyrite particles adhered. Additionally, some pyrrhotite fine particles were adsorbed on the surface of pyrite, and some agglomerated together; splitting occurred on the surface of pyrite, and a small amount of $S_{2}$ volatilized. In the second stage, most of the pores appeared on the surface of pyrite, and the thermal decomposition of the pyrite particles and pyrrhotite fine particles occurred when heated simultaneously, producing gas $S_{2}$ and volatilizing. The fine particles 
TABLE 2: Calculation results of the apparent activation energy of the three ore dust samples.

\begin{tabular}{|c|c|c|c|c|c|c|c|}
\hline Sample type & Function & Mechanism & $g(\alpha)$ & $\mathbf{R}^{2}$ & $\begin{array}{c}E \mathrm{Ea} / \\
\mathrm{kJ} \cdot \mathrm{mol}^{-1}\end{array}$ & $\mathrm{~A} / \mathrm{s}^{-1}$ & Model \\
\hline Pyrite & $\begin{array}{l}\text { Inverse Jander } \\
\text { equation }\end{array}$ & Three-dimensional diffusion, 3D & {$\left[(1+a)^{1 / 3}-1\right]^{2}$} & 0.9810 & 147.18 & $1.49 \times 10^{5}$ & a \\
\hline Pyrite & $\begin{array}{l}\text { Shrinkage spherical } \\
\text { (volume) }\end{array}$ & Shrinkage spherical & $3\left[1-(1-a)^{1 / 3}\right]$ & 0.9558 & 89.04 & $5.6 \times 10^{1}$ & $\mathrm{~b}$ \\
\hline $\begin{array}{l}\text { Mixed minerals } \\
(1: 1)\end{array}$ & Mampel power rule & $\begin{array}{l}\text { Phase boundary reaction (one- } \\
\text { dimensional, } n=2 \text { ) }\end{array}$ & $a^{2}$ & 0.9754 & 87.20 & $2.95 \times 10^{1}$ & c \\
\hline Pyrrhotite & Third order & Multistage reaction & $(1-a)^{-2}$ & 0.9914 & 27.21 & $3.70 \times 10^{5}$ & $\mathrm{~d}$ \\
\hline Pyrrhotite & Jander equation & $\begin{array}{l}\text { Three-dimensional diffusion, } \\
\text { spherical symmetry, 3D }\end{array}$ & {$\left[1-(1-a)^{1 / 3}\right]^{2}$} & 0.9657 & 41.59 & $2.01 \times 10^{3}$ & $\mathrm{e}$ \\
\hline
\end{tabular}

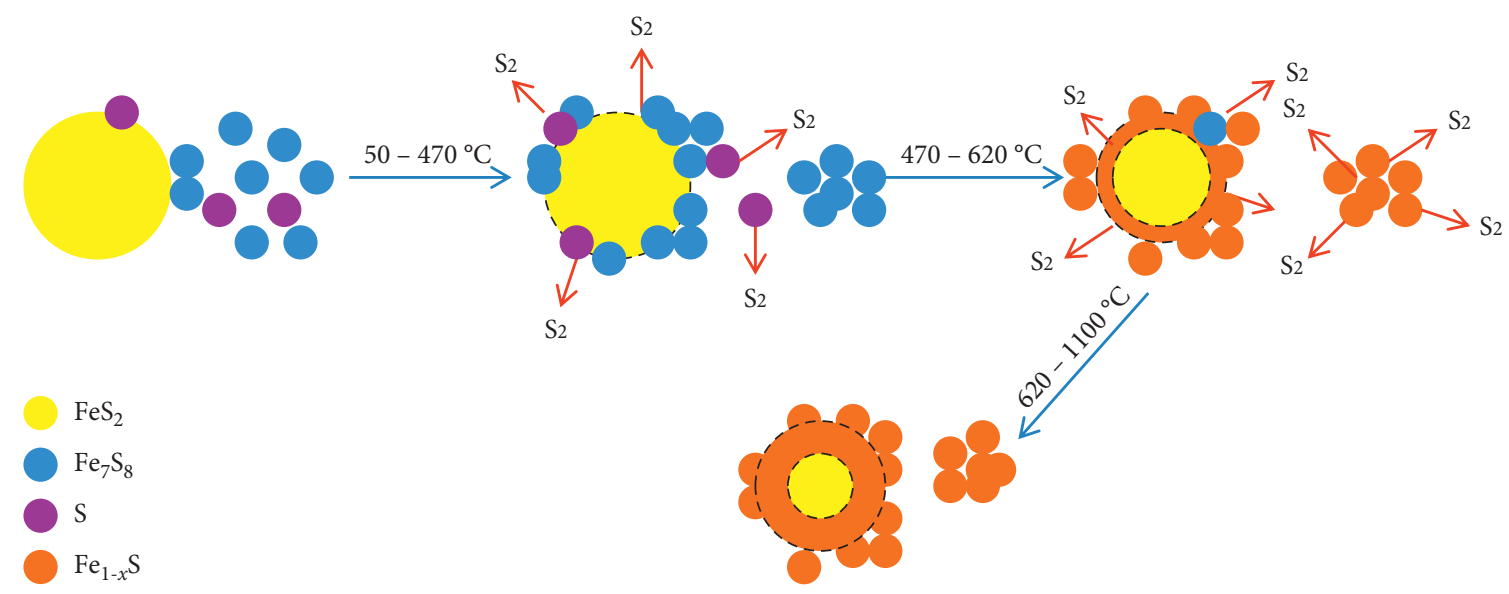

FIgURE 10: Thermal decomposition reaction model of the mixed minerals in $\mathrm{N}_{2}$ atmosphere.

adsorbed on the surface of pyrite and the agglomerated fine particles were further agglomerated by heat. Pyrite underwent a nuclear shrinkage reaction [16], resulting in a reduced particle volume. In the third stage, the amount of gas, $S_{2}$, gradually reduced. The large particles adsorbed with fine particles and the aggregated small particles were agglomerated and compact, showing hexagonal columns, and all of them reacted to form hexagonal pyrrhotite, $\mathrm{Fe}_{1-\mathrm{x}} \mathrm{S}$.

There are three reasons why pyrrhotite accelerated the thermal decomposition of mixed minerals. First, the adsorption of small particles increased the specific surface area of large particles, enhanced the thermal decomposition reaction activity, and accelerated thermal decomposition. This phenomenon can be confirmed from the results presented in Tables 1 and 2. Second, fine particles were adsorbed on the surface of the large pyrite particles because of the positive magnetic force of the Fe element in pyrrhotite. The precipitation of the negatively charged $S\left(S^{-1}\right)$ in pyrite was accelerated, resulting in the early appearance of pores on the surface of pyrite, which can be confirmed in Figure 8(b). Third, fine particles were adsorbed on the surface of large pyrite particles because the reaction temperature of the fine particles was relatively low, and the gas product, $S_{2}$, was volatilized earlier. The volatilization of the gas products produced by the fine particles increased the surface tension of the large pyrite particles, accelerated the surface splitting of the large pyrite particles, and reduced the thermal decomposition reaction temperature of pyrite, as shown in Figures $7(b)$ and $8(b)$.

\section{Conclusions}

The effect of pyrrhotite content on the thermal decomposition of the pyrite-pyrrhotite mixture in the $\mathrm{N}_{2}$ atmosphere was studied.

(1) The apparent activation energy of pyrrhotite was lower than that of the pyrite and pyrite-pyrrhotite mixture. With an increase in the pyrrhotite content, the specific surface area of the pyrite-pyrrhotite mixtures increased, resulting in a decrease in the reaction peak temperature at the thermal decomposition rate.

(2) Pyrrhotite agglomerated more when pyrrhotite was decomposed. The fine pyrrhotite particles adsorbed on the surface of pyrite blocked the pores of pyrite, resulting in a decrease in the total amount of gas product $\left(\mathrm{S}_{2}\right)$ and the total mass loss of the pyritepyrrhotite mixtures.

(3) The thermal decomposition products of monoclinic pyrrhotite and pyrite-pyrrhotite mixtures at $1100^{\circ} \mathrm{C}$ were mainly hexagonal pyrrhotite $\left(\mathrm{Fe}_{1-\mathrm{x}} \mathrm{S}\right)$, while the thermal decomposition product of pyrite was troilite (FeS). 


\section{Data Availability}

The data used to support the findings of this study are included within the article.

\section{Conflicts of Interest}

The authors declare that they have no conflicts of interest.

\section{Acknowledgments}

This work was supported by the National Natural Science Foundation of China (NSFC 51874149 and 51364010).

\section{References}

[1] M. K. Ji, E. D. Gee, H. S. Yun et al., "Inhibition of sulfide mineral oxidation by surface coating agents: batch and field studies," Journal of Hazardous Materials, vol. 229-230, no. 230, pp. 298-306, 2012.

[2] Q. Huang and R. Honaker, "Recent trends in rock dust modifications for improved dispersion and coal dust explosion mitigation," Journal of Loss Prevention in the Process Industries, vol. 41, pp. 121-128, 2016.

[3] Q. Li, Q. Tao, C. Yuan, Y. Zheng, G. Zhang, and J. Liu, "Investigation on the structure evolution of pre and post explosion of coal dust using X-ray diffraction," International Journal of Heat and Mass Transfer, vol. 120, pp. 1162-1172, 2018.

[4] B. Luo, T. Peng, and H. Sun, "Innovative methodology for sulfur release from copper tailings by the oxidation roasting process," Journal of Chemistry, vol. 2020, pp. 1-11, 2020.

[5] A. Yadollahi, H. Abdollahi, F. D. Ardejani, M. Mirmohammadi, and S. Magdouli, "Bio-oxidation behavior of pyrite, marcasite, pyrrhotite, and arsenopyrite by sulfur- and iron-oxidizing acidophiles," Bioresource Technology Reports, vol. 15, pp. 1-8, 2021.

[6] F. Huang, L.-Q. Zhang, B.-J. Yi, Z.-J. Xia, and C.-G. Zheng, "Transformation pathway of excluded mineral pyrite decomposition in $\mathrm{CO}_{2}$ atmosphere," Fuel Processing Technology, vol. 138, pp. 814-824, 2015.

[7] R. Walker, A. D. Steele, and D. T. B. Morgan, "Pyrophoric nature of iron sulfides," Industrial \& Engineering Chemistry Research, vol. 35, no. 5, pp. 1747-1752, 1996.

[8] Y. Q. Yu and J. C. Fan, "Research on explosion characteristics of sulfur dust and risk control of the explosion," Procedia Engineering, vol. 84, pp. 449-459, 2014.

[9] L. M. Li, C. Wu, F. Q. Yang, and G. Gao, "Study on relevant factors during measuring sulfide ore pile temperature in the state of self-heating by infrared spectroscopy," Fire Safety Science, vol. 17, no. 1, pp. 49-53, 2008.

[10] Y.-z. Rao, C.-s. Tian, W. Xu, C.-y. Xiao, B.-y. Yuan, and Y. Yu, "Explosion pressure and minimum explosible concentration properties of metal sulfide ore dust clouds," Journal of Chemistry, vol. 2020, pp. 1-12, 2020.

[11] A. Aracena, O. Jerez, R. Ortiz, and J. Morales, "Pyrite oxidation kinetics in an oxygen-nitrogen atmosphere at temperatures from 400 to $500^{\circ} \mathrm{C}$," Canadian Metallurgical Quarterly, vol. 55, no. 2, pp. 195-201, 2016.

[12] X. Li, Z. Chen, X. Chen, Y. Zhang, and Y. Niu, "Effects of mechanical activation methods on thermo-oxidation behaviors of pyrite," Journal of Wuhan University of TechnologyMaterials Science Edition, vol. 30, no. 5, pp. 974-980, 2015.
[13] A. W. Coats and N. F. H. Bright, "The kinetics of the thermal decomposition of pyrite," Canadian Journal of Chemistry, vol. 44, no. 10, pp. 1191-1195, 1996.

[14] G. L. Hu, K. D. Johansen, S. Wedel, and J. P. Hansen, "Decomposition and oxidation of pyrite," Progress in Energy and Combustion Science, vol. 32, no. 3, pp. 295-314, 2016.

[15] Y. Hong and B. Fegley Jr., "The kinetics and mechanism of pyrite thermal decomposition," Berichte der Bunsen-Gesellschaft für Physikalische Chemie, vol. 101, no. 12, pp. 1870-1881, 1997.

[16] I. C. Hoare, H. J. Hurst, W. I. Stuart, and T. J. White, “Thermal decomposition of pyrite. Kinetic analysis of thermogravimetric data by predictor-corrector numerical methods," Journal of the Chemical Society, Faraday Transactions 1: Physical Chemistry in Condensed Phases, vol. 84, no. 9, pp. 3071-3077, 1988.

[17] Y. D. Shi, T. H. Chen, P. Li, X. Zhu, and Y. Yang, "The phase transition of pyrite thermal decomposition in nitrogen gas," Geological Journal of China Universities, vol. 21, no. 4, pp. 577-583, 2015.

[18] L. Wang, Y. Pan, J. Li, and H. Qin, "Magnetic properties related to thermal treatment of pyrite," Science in China Series D: Earth Sciences, vol. 51, no. 8, pp. 1144-1153, 2008.

[19] H. Y. Li and S. H. Zhang, "Detection of mineralogical changes in pyrite using measurements of temperature-dependence susceptibilities," Chinese Journal of Geophysics, vol. 48, no. 6, pp. 1384-1391, 2005.

[20] C. M. V. B. Almeida and B. F. Giannetti, "The electrochemical behavior of pyrite-pyrrhotite mixtures," Journal of Electroanalytical Chemistry, vol. 553, pp. 27-34, 2003.

[21] E. N. Selivanov, R. I. Gulyaeva, and A. D. Vershinin, "Thermal expansion and phase transformations of natural pyrrhotite," Inorganic Materials, vol. 44, no. 4, pp. 438-442, 2008.

[22] E. J. Schwarz and D. J. Vaughan, "Magnetic phase relations of pyrrhotite," Journal of Geomagnetism and Geoelectricity, vol. 24, no. 4, pp. 441-458, 1972.

[23] G. S. Li, H. W. Cheng, X. L. Xiong et al., "In-situ high temperature X-ray diffraction study on the phase transition process of polymetallic sulfide ore," IOP Conference Series: Materials Science and Engineering, vol. 191, pp. 1-6, 2017.

[24] A. V. Powell, P. Vaqueiro, K. S. Knight, L. C. Chapon, and R. D. Sánchez, "Structure and magnetism in synthetic pyrrhotite $\mathrm{Fe}_{7} \mathrm{~S}_{8}$ : a powder neutron-diffraction study," Physical Review B, vol. 70, no. 1, pp. 1-12, 2004.

[25] T. Kennedy and B. T. Sturman, "The oxidation of iron (II) sulphide," Journal of Thermal Analysis, vol. 8, no. 2, pp. 329-337, 1975.

[26] J. G. Dunn and L. C. Mackey, "The measurement of the ignition temperatures of commercially important sulfide minerals," Journal of Thermal Analysis, vol. 38, no. 3, pp. 487-494, 1992.

[27] F. Q. Yang, Y. Z. Song, and W. F. Zhu, "Fractal characteristics of adsorption hole of FeS-FeS 2 compounds," Journal of Fuzhou University (Natural Science Edition), vol. 47, no. 1, pp. 118-123, 2019.

[28] H. P. Hu, Q. Y. Chen, Z. L. Yin, and P. M. Zhang, “Thermal behaviors of mechanically activated pyrites by thermogravimetry (TG)," Thermochimica Acta, vol. 398, no. 1-2, pp. 233-240, 2003.

[29] Gb/T, 6730 65, China Standards, Iron Ores-Determination of Total Iron content-Titanium (III) Chloride Reduction Potassium Dichromate Titration Methods (Routine Methods), State Bureau of Technical Supervision, Beijing, China, 2009.

[30] YS/T 575.17, China Standards, Methods for Chemical Analysis of Bauxite - Part 17: Determination of Sulfur Content Direct 
Combustion-Iodometric Method, National Development and Reform Commission, Beijing, China, 2007.

[31] F.-q. Yang, C. Wu, Y. Cui, and G. Lu, "Apparent activation energy for spontaneous combustion of sulfide concentrates in storage yard," Transactions of Nonferrous Metals Society of China, vol. 21, no. 2, pp. 395-401, 2011.

[32] R. Soundararajan, P. R. Amyotte, and M. J. Pegg, "Explosibility hazard of iron sulphide dusts as a function of particle size," Journal of Hazardous Materials, vol. 51, no. 1-3, pp. 225-239, 1996.

[33] W. Cao, Q. Qin, W. Cao et al., "Experimental and numerical studies on the explosion severities of coal dust/air mixtures in a 20-L spherical vessel," Powder Technology, vol. 310, pp. 17-23, 2017.

[34] T. Miyazaki and T. Sasaki, "A comparison of X-ray stress measurement methods based on the fundamental equation," Journal of Applied Crystallography, vol. 49, no. 2, pp. 426-432, 2016.

[35] F. R. A. Jorgensen and F. J. Moyle, "Phases formed during the thermal analysis of pyrite in air," Journal of Thermal Analysis, vol. 25, no. 2, pp. 473-485, 1982.

[36] F. R. A. Jorgensen and F. J. Moyle, "Gas diffusion during the thermal analysis of pyrite," Journal of Thermal Analysis, vol. 31, no. 1, pp. 145-156, 1986.

[37] R. Z. Hu, S. L. Gao, and F. Q. Zhao, Thermal Analysis Kinetics, Science Press, Beijing, China, 2nd edition, 2008.

[38] W. Lv, D. Yu, J. Wu, L. Zhang, and M. Xu, "The chemical role of $\mathrm{CO}_{2}$ in pyrite thermal decomposition," Proceedings of the Combustion Institute, vol. 35, no. 3, pp. 3637-3644, 2015.

[39] L. F. Su, G. Q. Zhuo, H. W. Song, J. Y. Yang, and K. Y. Jiang, "Effect of $\mathrm{Al}_{2} \mathrm{O}_{3}$ and $\mathrm{SiO}_{2}$ inert-fillers on the microstructural evolution and high temperature oxidation resistance of $\mathrm{B}$ modified silicides coatings prepared by pack cementation technology," Coatings, vol. 11, no. 6, pp. 1-13, 2021. 